\title{
Effect of natural gel product on bovine dentin erosion in vitro
}

\begin{abstract}
André de Carvalho SALES-PERES ${ }^{1}$, Juliane Avansini MARSICANO ${ }^{1}$, Rudan Paraíso GARCIA1 ${ }^{1}$ Moacir Rossi FORIM², Maria Fatima das Graças Fernandes da SILVA², Sílvia Helena de Carvalho SALES-PERES ${ }^{1}$
\end{abstract} 1- Department of Pediatric Dentistry, Orthodontics and Community Health, Bauru School of Dentistry, University of São Paulo, Bauru, SP, Brazil.
2- Department of Chemistry, Laboratory of Natural Products, Federal University of São Carlos, São Carlos, SP, Brazil.

Corresponding address: Silvia Helena de Carvalho Sales Peres - Departamento de Odontopediatria, Ortodontia e Saúde Coletiva - Faculdade de Odontologia de Bauru - Universidade de São Paulo - Al. Octávio Pinheiro Brisolla, 9-75 - Bauru - SP - 17012-901 - Brasil - Phone: + 551432358260 - Fax + 5514 32358260 - e-mail: shcperes@usp.br

Submitted: March 12, 2013 - Modification: May 2, 2013 - Accepted: November 1, 2013

\section{ABSTRACT}

\begin{abstract}
$\mathrm{O}$ bjective: To evaluate the efficacy of Neem (Azadirachta indica) experimental gel for the prevention of erosive wear on bovine dentin, in vitro. Material and Methods: One hundred dentin blocks were allocated into 5 experimental groups (20 samples each): C (control group, without gel); CG (control group, only base gel); F (fluoride gel, 1.23\% NaF; pH 4.1, Dentsply; Brazil); N (Neem gel, 10\% neem extract; pH 4.1, manipulation); NF (Neem+fluoride gel, $10 \%$ Neem extract and $1.23 \% \mathrm{NaF} ; \mathrm{pH} 4.1$, manipulation). The blocks were stored in artificial saliva for 24 hours. After this, they were submitted to six alternating re- and demineralization cycles. The blocks were analyzed for wear (profilometry). The results were submitted to statistical analysis by ANOVA and Tukey tests $(P<0.05)$. Results: The mean wear $( \pm S D, \mu \mathrm{m})$ was shown as follows in groups: $C(13.09 \pm 0.99)$, CG $(10.60 \pm 1.99), F(10.90 \pm 1.44), N(12.68 \pm 1.13)$ and NF (10.84 1.65$)$. All gels showed some preventive action when compared with control group. However, significant differences were found only between Neem +fluoride gel and fluoride gel. Conclusion: A single application of a neem-containing fluoride gel reduced dentin erosion, thus it is a possible alternative in reducing dental wear. Further research should investigate the action mechanism and the synergism between them.
\end{abstract}

Key words: Tooth erosion. Demineralization. Azadirachta indica. Topical fluorides. Dentin.

\section{INTRODUCTION}

Dental erosion is the loss of dental hard tissue through chemical etching and dissolution by acids of nonbacterial origin $9,11,16$. There is increasing incidence and prevalence of dental erosion $3,6,10,14$ and it is important to identify agents that might protect the tooth surface from demineralization 22 .

There is evidence that fluoride mainly works topically by promoting remineralization and impeding the demineralization of hard tooth tissue ${ }^{20}$. In particular, intensive fluoridation by a combined application of fluoridated toothpaste, fluoridated mouth rinse and fluoride gel, or the application of highly concentrated fluorides, might be effective in decreasing the progression of erosive lesions ${ }^{22}$. However, the role of fluoride in erosion is still controversial, as reviews of fluoride action in reducing dental erosion have demonstrated that the erosive potential was not minimized with the use of fluoride ${ }^{21}$.

In the past, chewing sticks were used for oral hygiene, and it is believed that this was the precursor to the modern day toothbrush. Currently, Neem (Azadirachta indica) "chewing sticks" are used in certain Asian and African countries as an oral hygiene device ${ }^{2,24}$. The Neem tree contains different bioactive compounds, such as proteins (amino acids) and carbohydrates (polysaccharides), sulphurous compounds, polyphenolics such as flavonoids and their glycosides, dihydrochalcone, coumarin and tannins, aliphatic compounds, etc $^{5}$, which are of interest because of their health beneficial effects. Extracts of Neem have been found to have immunomodulatory, anti-inflammatory and anticarcinogenic properties ${ }^{13}$. 
The literature has not yet presented any study analyzing Neem and dental erosion. Therefore, the aim of this study was to evaluate the efficacy of experimental Neem gel and fluoride gel for the prevention of erosive wear on bovine dentin blocks exposed to a soft drink, in vitro.

\section{MATERIAL AND METHODS}

\section{Preparation of dentin specimens}

Bovine permanent incisors were stored in $0.5 \%$ thymol solution for 30 days until used for sample preparation. The teeth were sectioned at the cemento-enamel junction using a diamond disk (Isomet 1000; Buehler, Lake Bluff, IL, USA). After this, two parallel diamond disks separated by a 4 $\mathrm{mm}$ spacer were used to cut 1-2 fragments from the crown of each bovine incisor. Enamel surface of the blocks were removed with the aid of drills to expose the dentin. Enamel and dentin surfaces were then planed with water-cooled carborundum paper (320, 600 and 1200 grit $\mathrm{Al}_{2} \mathrm{O}_{3}$ papers; Buehler, Lake Bluff, IL, USA) and polished in the dentin with felt pads and diamond spray ( $1 \mu \mathrm{m}$; Buehler, Lake Bluff, $\mathrm{IL}$, USA), which is necessary to enable profilometric measurement.

The surface microhardness of dentin samples (five indentations in different regions of the blocks, 25 g, 5 s, HMV-2000; Shimadzu Corporation, Tokyo, Japan) was determined as a criterion for stratified allocation of dentin specimens of the same tooth among 5 groups (20 dentin samples in each). Blocks that presented $10 \%$ below and $10 \%$ above the mean value were excluded from the sample.

In order to maintain reference surfaces for determining lesion depth, two layers of nail varnish (Risqué, Niasi, Taboão da Serra, São Paulo, Brazil) were applied on half of the specimen surfaces. After preparation, the samples were stored in artificial saliva for $24 \mathrm{~h}$ at $37^{\circ} \mathrm{C}$ to avoid dehydration until use for the experiment. The composition of the artificial saliva was: $1.5 \mathrm{mmol} / \mathrm{L} \mathrm{Ca}\left(\mathrm{NO}_{3}\right)_{2} . \mathrm{H}_{2} \mathrm{O} ; 0.9$ $\mathrm{mmol} / \mathrm{L} \mathrm{Na}_{2} \mathrm{HPO}_{4} .2 \mathrm{H}_{2} \mathrm{O} ; 150 \mathrm{mmol} / \mathrm{L} \mathrm{KCl} ; 0.1 \mathrm{~mol} / \mathrm{L}$ $\mathrm{H}_{2} \mathrm{NC}\left(\mathrm{CH}_{2} \mathrm{OH}\right)_{3}$ (TRIS); $0.05 \mathrm{NaF}$ pH 7.016,19.

\section{Study design}

One hundred specimens with a mean surface microhardness between 40 and $64 \mathrm{KHN}(46.42 \pm 5.96)$ were randomly divided into 5 groups: C (control group, without gel); CG (control group, only base gel); F (fluoride gel, 1.23\% NaF; pH 4.1, Dentsply; Brazil); N (Neem gel, 10\% Neem extract; pH 4.1, manipulation); NF (Neem+fluoride gel, 10\% Neem extract and $1.23 \% \mathrm{NaF}$; $\mathrm{pH} 4.1$, manipulation). Before exposure to acid, the samples were pretreated with one of the respective gels. A thin layer of gel was applied to the dentin surface with a microbrush. After $4 \mathrm{~min}$, the gel was removed from the surface with a cotton roll and was rinsed with deionized water.

The samples of all groups $(n=20)$ were submitted to demineralization-remineralization regimes. Specimens were consecutively cycled through this regimen six times. One complete cycle consisted of the following steps: (1) demineralization in 30 $\mathrm{mL}$ of the beverage (Coca-Cola ${ }^{\circledR}$, Cia de Bebidas Ipiranga, Ribeirão Preto, Brazil) for 10 min under gentle agitation; (2) remineralization in $30 \mathrm{~mL}$ of artificial saliva for $60 \mathrm{~min}$ at $37^{\circ} \mathrm{C}$.

\section{Profillometric measurement}

At the end of experimental phase, the nail varnish on the reference surfaces was carefully removed with acetone-soaked cotton wool. Surface profiles of the dentin specimens were obtained with a contact profilometer (Hommel Tester T 1000, Hommelwerke, VS, Schwenningen, Germany). To determine dentin loss, the tape was removed and 5 profiles were recorded at exactly the same sites, as those used for baseline measurement. The profile scans were performed in the center of each specimen at 250 $\mu \mathrm{m}$ intervals.

Treatment scans were superimposed and the average depth of the area under the curve in the eroded area was calculated with specially designed software. The results of the 5 scans were averaged for each specimen.

\section{Statistical analysis}

Mean and standard deviation (SD) for dentin loss in each group were calculated and statistically analyzed by ANOVA and Tukey tests for individual comparisons among the groups, for which STATISTICA version 7.0 (Sat-Soft-USA) was used.

Table 1- Wear $(\mu \mathrm{m})$ and standard deviation $( \pm S D)$ of dentin, with different treatments

\begin{tabular}{clll}
\hline Treatments & $\mathbf{N}$ & Mean & $\mathbf{\pm S D}$ \\
\hline Control group & 20 & 13.095 & $\pm 0.999^{\mathrm{a}}$ \\
Control base gel group & 20 & 10.693 & $\pm 1.986^{\mathrm{b}}$ \\
\hline Neem gel & 20 & 12.676 & $\pm 1.133^{\mathrm{a}}$ \\
Fluoride gel & 20 & 10.902 & $\pm 1.441^{\mathrm{b}}$ \\
Neem+fluoride gel & 20 & 10.848 & $\pm 1.655^{\mathrm{b}}$ \\
\hline
\end{tabular}

Different lower case letters indicate statistical significance between the groups $(P<0.05)$ 
The level of significance was set at $5 \%$.

\section{RESULTS}

With regard to the effectiveness of the gels tested for the prevention of dentin erosion, all showed some action when compared with the control group. However, significant differences were found only between Neem+fluoride gel and fluoride gel. Mean dentin loss in the experimental groups is presented in Table 1.

\section{DISCUSSION}

The development of chemotherapeutic agents able to inhibit dental plaque formation has been of great interest to dental researchers and clinical dentists. Nevertheless, due to the decreasing occurrence of dental caries in many societies, attention has been focused on tooth wear from erosion, abrasion and attrition ${ }^{17}$, and the development of agents capable of preventing or/and inhibiting dental wear.

Recent research has drawn attention to the role of various compounds in the prevention and therapy of dental erosion, such as fluoride compounds (acidulated phosphate fluoride, sodium fluoride, stannous fluoride, titanium and zirconium fluoride) and ferrous sulphate ${ }^{8,12}$.

Fluoride ions appear to increase the microhardness of enamel, thereby improving its resistance to acid dissolution affecting de- and remineralization and causing the precipitation of $\mathrm{CaF}_{2}$-like material on eroded dental surfaces ${ }^{4,12}$. However, most of the evidence on the effect of fluoride has been based on laboratory investigations and the role of fluoride application in the prevention of dental erosion is still controversially discussed ${ }^{4,12}$.

In this study, the fluoride gel was shown to be effective for the prevention of dental erosion when compared with the control group. Similar results have been found in other studies that evaluated the effects of fluoride on mineral loss in an erosion process in human dentin using in situ demineralization and remineralization $\mathrm{cycles}^{7,18}$.

Studies that have compared the effectiveness of fluoride gel and other substances in solutions in in vitro cycles of acid challenges (erosion) and remineralization have demonstrated that the fluoride gel has the same effect as other gels have on dentin, with regard to reducing the progression of erosion ${ }^{6,18,23}$.

However, in the present study, the group in which only the gel containing Neem (Azadirachta indica) was applied demonstrated a lower effectiveness than that shown in the fluoride gel group. On the other hand, the Neem+fluoride gel showed better efficiency in the prevention of dental erosion, which was statistically similar to that of fluoride gel. Therefore, the compounds might act synergistically or additively with regard to inhibition of demineralization.

This result may be due to the composition of Neem, which contains the alkaloid margosine, resins, gum, chloride, fluoride, silica, sulfur, oils, sterols, saponins, flavonoids, tannins, and calcium ${ }^{15}$.

Tannins and resins supposedly have an astringent effect on the mucous membrane, and they form a layer over enamel, thus providing protection against dental caries as found in the study of Prashant, et al. ${ }^{15}$ (2007). This property can also help in the prevention of tooth wear, because the biofilm will protect the dental hard tissue against acids, abrasion and attrition.

In the Neem+fluoride gel group, the Neem component may function as a mechanical barrier, while the fluoride component as a chemical protection of the tooth surface, which may help to prevent the development of erosive lesions. There is evidence that topical fluoride mainly works by promoting remineralization and impeding the demineralization of tooth hard tissue ${ }^{20}$.

The present study was a pioneer in the use of Neem-containing gel as a preventive method against dental erosion. The use of natural products with therapeutic actions have always had great popular acceptance, and they are more frequently used because they usually cause no side effects. Furthermore, natural products, such as Neem gel, can be used to treat various diseases, including the prevention of dental caries and periodontal diseases, because studies have suggested that Neem extract is capable of reducing the ability of some streptococci, such as Streptococcus mutans, to colonize tooth surfaces ${ }^{1,15}$.

Thus, this natural product containing fluoride is a good alternative for use as a protective agent against acid challenges, considering that its consistency allows obstruction of the dentinal tubules, and for the prevention of bacterial oral diseases.

\section{CONCLUSION}

Under the conditions of the present study, it can be concluded that a single application of Neem-containing fluoride gel seems to be the best alternative to partially reduce erosive wear in dentin. Further research should investigate the action mechanism and the synergism between these compounds.

\section{ACKNOWLEDGEMENTS}

The research was supported by a grant from FAPESP - São Paulo Research Foundation (08/109224). 


\section{REFERENCES}

1- Almas K. The antimicrobial effects of extracts of Azadirachta indica (Neem) and Salvadora persica (Arak) chewing sticks. Indian J Dent Res. 1999;10:23-6.

2- Almas K. The effect of Salvadora persica extract (miswak) and chlorhexidine gluconate on human dentin: a SEM study. J Contemp Dent Pract. 2002;3:27-35.

3- Amaechi BT, Higham SM. Dental erosion: possible approaches to prevention and control. J Dent. 2005;33:243-52.

4- Bartlett D. Etiology and prevention of acid erosion. Compend Contin Educ Dent. 2009;30:616-20.

5- Biswas K, Chattopadhyay I, Banerjee RK, Bandyopadhyay U. Biological activities and medicinal properties of neem (Azadirachta indica). Curr Science. 2002;82:1336-45.

6- Bueno MG, Marsicano JA, Sales-Peres SH. Preventive effect of iron gel with or without fluoride on bovine enamel erosion in vitro. Aust Dent J. 2010;55:177-80.

7- Ganss C, Klimek J, Brune V, Schürmann A. Effects of two fluoridation measures on erosion progression in human enamel and dentine in situ. Caries Res. 2004;38:561-6.

8- Ganss C, Lussi A, Sommer N, Klimek J, Schlueter N. Efficacy of fluoride compounds and stannous chloride as erosion inhibitors in dentine. Caries Res. 2010;44:248-52.

9- Kato MT, Lancia M, Sales-Peres SH, Buzalaf MA. Preventive effect of commercial desensitizing toothpastes on bovine enamel erosion in vitro. Caries Res. 2010;44:85-9.

10- Lussi A, Hellwig E, Zero D, Jaeggi T. Erosive tooth wear: diagnosis, risk factors and prevention. Am J Dent. 2006;19:319-25. 11- Lussi A, Jaeggi T, Zero D. The role of diet in the aetiology of dental erosion. Caries Res. 2004;38:34-44.

12- Magalhães AC, Wiegand A, Rios D, Honório HM, Buzalaf MA. Insights into preventive measures for dental erosion. J Appl Oral Sci. 2009;17:75-86.

13- Manikandan P, Letchoumy PV, Gopalakrishnan M, Nagini S. Evaluation of Azadirachta indica leaf fractions for in vitro antioxidant potential and in vivo modulation of biomarkers of chemoprevention in the hamster buccal pouch carcinogenesis model. Food Chem Toxicol. 2008;46:2332-43.
14- Murakami C, Bonecker M, Corrêa MS, Mendes FM, Rodrigues $\mathrm{CR}$. Effect of fluoride varnish and gel on dental erosion in primary and permanent teeth. Arch Oral Biol. 2009;54:997-1001.

15- Prashant GM, Chandu GN, Murulikrishna KS, Shafiulla MD. The effect of mango and neem extract on four organisms causing dental caries: Streptococcus mutans, Streptococcus salivavius, Streptococcus mitis, and Streptococcus sanguis: an in vitro study. Indian J Dent Res. 2007;18:148-51.

16- Sales-Peres SH, Pessan JP, Buzalaf MA. Effect of an iron mouthrinse on enamel and dentine erosion subjected or not to abrasion: an in situ/ex vivo study. Arch Oral Biol. 2007;52:128-32. 17- Sales-Peres SHC, Goya S, Araújo JJ, Sales-Peres A, Lauris JR, Buzalaf MA. Prevalence of dental wear among 12-year-old Brazilian adolescents using a modification of the tooth wear index. Public Health. 2008; 122:942-8.

18- Schlueter N, Ganss C, Mueller U, Klimek J. Effect of titanium tetrafluoride and sodium fluoride on erosion progression in enamel and dentine in vitro. Caries Res. 2007;41:141-5.

19- Vieira AE, Delbem AC, Sassaki KT, Rodrigues E, Cury JA, Cunha RF. Fluoride dose response in $\mathrm{pH}$-cycling models using bovine enamel. Caries Res. 2005;39:514-20.

20- Wiegand A, Attin T. Influence of fluoride on the prevention of erosive lesions - a review. Oral Health Prev Dent. 2003;1:245-53. 21- Wiegand A, Attin T. Occupational dental erosion from exposure to acids: a review. Occup Med (Lond). 2007;57:169-76.

22- Wiegand A, Gutsche M, Attin T. Effect of olive oil and an oliveoil-containing fluoridated mouthrinse on enamel and dentin erosion in vitro. Acta Odont Scan. 2007;65:357-61.

23- Wiegand A, Hiestand B, Sener B, Magalhães AC, Roos M, Attin T. Effect of TiF4, ZrF4, HfF4 and AmF on erosion and erosion/abrasion of enamel and dentin in situ. Arch Oral Biol. 2010;55:223-8.

24- Wolinsky LE, Mania S, Nachnani S, Ling S. The inhibiting effect of aqueous Azadirachta indica (Neem) extract upon bacterial properties influencing in vitro plaque formation. J Dent Res. $1996 ; 75: 816-22$. 